\title{
Treino do bacio: estudo observacional numa amostra de crianças saudáveis entre os 18 e os 42 meses
}

Ângela Pereira, ${ }^{1}$ Jean-Pierre Gonçalves, ${ }^{2}$ Ângela Oliveira, ${ }^{1}$ Liliana Abreu, ${ }^{1}$ Manuela Costa Alves, ${ }^{2}$ Aparício Braga, ${ }^{3}$ Sofia Martins ${ }^{2}$

\section{RESUMO}

Introdução: O treino do bacio (TB) ou controlo de esfíncteres é uma etapa importante no desenvolvimento infantil. Existem poucos estudos e diretrizes sobre esta temática e, da pesquisa bibliográfica efetuada, não há dados epidemiológicos nacionais. Este estudo pretende descrever o processo do TB numa amostra de crianças portuguesas, determinando variáveis biológicas, sociais e económicas envolvidas e métodos aplicados.

Metodologia: Efetuado um estudo transversal, observacional e analítico, selecionando uma amostra de conveniência na consulta de saúde infantil e juvenil de três centros de saúde. Recolhemos os dados através de um questionário aos pais de crianças entre 18 e 42 meses (M). Excluímos patologias crónicas que interfiram na aquisição de controlo de esfíncteres, gémeos ou dados insuficientes.

Resultados: Foram realizados inquéritos aos pais de 83 crianças com idades compreendidas entre $18 \mathrm{M}$ e $42 \mathrm{M}$, das quais 24 não deram início ao TB. Das 59 restantes, 31 eram rapazes e a média de idades 31M [desvio-padrão $(D P)=9$ ]. A idade média de início e término do TB foi $22 \mathrm{M}(D P=7)$ e $27 \mathrm{M}(D P=7)$, respetivamente (mais cedo nas raparigas). Crianças do meio rural, filhos de mães empregadas e com escolaridade $\leq 5$ anos iniciaram o TB mais cedo. No total, 20 completaram o TB, após uma duração em média de 3M (mediana 2M [0-16M]). O grupo que iniciou mais cedo completou com menor idade o TB $(p=0,005)$; contudo, a duração até aquisição de controlo de esfíncteres foi maior $(p=0,046)$. Os métodos aplicados mais vezes pelos cuidadores foram reforço positivo e mostrar exemplos.

Conclusões: A transição para TB apresenta grande variabilidade de fatores; nesta amostra, crianças do sexo feminino, filhos de mães empregadas e com menos instrução académica, a viver em meio rural, iniciaram o TB mais cedo.

Existiu uma diferença estatisticamente significativa entre iniciar o TB com menor idade e a aquisição de controlo de esfíncteres mais precoce, mas também com maior duração do TB.

Palavras-chave: Controlo Esfincteriano; Crianças; Desenvolvimento Infantil; Treino do Bacio.

\section{INTRODUÇÃO E OBJETIVOS}

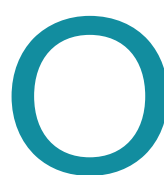
treino do bacio (TB) ou controlo de esfíncteres é uma etapa importante no desenvolvimento infantil, simbolizando a aquisição de novas competências para a sua autonomia, o que o torna um desafio para a criança, pais e médicos assistentes. ${ }^{1}$

'Médica Interna de Pediatria, Serviço de Pediatria, Hospital de Braga. ${ }^{2}$ Médica Pediatra, Serviço de Pediatria, Hospital de Braga.

${ }_{3}^{3}$ Médico Assistente de Medicina Geral e Familiar, Unidade de Cuidados de Saúde Personalizados Infias (Braga), Centro de Saúde de Braga.
Apesar de ser uma fase já ultrapassada por gerações de famílias e médicos, continua sem existir consenso acerca do melhor método ou mesmo uma definição universal do conceito "treino do bacio". ${ }^{1-2}$ Esta incerteza ocorre, em parte, pela vasta variabilidade de preferências e expectativas parentais. A questão muitas vezes colocada pelos pais é em que idade se deve iniciar o TB e não há uma resposta única. Diversos fatores têm influência, como o sexo, desenvolvimento psicomotor individual, expectativas dos cuidadores, cultura, exigências sociais e acontecimentos stressantes (divórcio 
dos pais, morte de um familiar, nascimento de um irmão ou a mudança de habitação). ${ }^{3}$ Existem também poucos estudos comparando estratégias e torna-se, assim, difícil estabelecer recomendações baseadas na evidência. ${ }^{2}$

Pesquisando em sociedades internacionais de pediatria de diferentes países, encontramos orientações em apenas três delas: Academia Americana de Pediatria ${ }^{4}$ Sociedade Canadiana de Pediatria ${ }^{5}$ e Academia Americana de Médicos de Família. ${ }^{6}$ Nestas recomendações, a linha orientadora segue preferencialmente $o$ "método passivo/orientado pela criança", mas verifica-se que ao longo dos tempos outros métodos têm sido utilizados com boa aceitação. ${ }^{1,7}$

O "método passivo/orientado pela criança", descrito originalmente por Brazelton, ${ }^{8}$ enfatiza a importância de a criança estar preparada para o treino, tentando minimizar o stress associado. Quando a criança adquirir um conjunto de competências passa-se então ao início do TB, oferecendo o bacio e passando do progresso de simplesmente se sentar nele para, gradualmente, o utilizar corretamente e ser encorajado com os sucessos alcançados. Aborda-se o tema dos "acidentes", mas sem estratégias punitivas. Este método dura habitualmente semanas a meses até ter sucesso na aquisição de controlo de esfíncteres.

Em contraste, o "treino num dia", proposto por Foxx e Azrin, ${ }^{9}$ envolve um período intenso de instruções para aquisição do controlo de esfíncteres em $24-48$ horas. $\mathrm{O}$ treino geralmente é iniciado com a ajuda de uma boneca que pode molhar o bacio para demonstrar as ações pretendidas. A criança é depois incentivada a imitar a boneca e, ao mesmo tempo, é-lhe fornecida uma quantidade reforçada de líquidos para estimular a micção. A criança é frequentemente lembrada do que se pretende e a cada 3-5 minutos verifica-se se se mantém seca, apostando no reforço positivo (elogios, brinquedos ou comida) a cada momento bem sucedido. Se acontecerem "acidentes", a criança será reprimida e terá a responsabilidade de trocar para roupa seca.

Menos conhecido, mas aplicado por longos anos em diversas áreas geográficas como a China, Índia, África, América do Sul e partes da Europa, é o método "assistido pelo cuidador". ${ }^{10}$ De Vries et al ${ }^{11}$ estudaram este método numa tribo africana, “The Digo", registando sucesso no TB no primeiro ano de vida, fundamentado por um envolvimento muito ativo e sistematizado por parte do cuidador que aprende a reconhecer os sinais dados pela criança antes da eliminação intestinal e vesical e aproveitando-os para a treinar, sem castigos, sem punições.

Em Portugal não existem diretrizes e, da pesquisa bibliográfica efetuada, não há dados epidemiológicos acerca do TB.

Este estudo pretende descrever o processo do TB numa amostra de crianças portuguesas, determinando variáveis biológicas, sociais e económicas envolvidas e métodos aplicados.

\section{MÉTODOS}

\section{Amostra}

Amostra de conveniência que incluiu crianças com idades compreendidas entre os 18 e os 42 meses (M) (total de 83 crianças), seguidas em consulta de saúde infantil e juvenil, de três centros de saúde, de zonas rurais e urbanas, no norte do país, contando com a participação de três investigadores.

\section{Procedimento}

Efetuamos um estudo transversal, observacional e analítico. Durante um período de três meses (outubro a dezembro de 2012) foi pedido aos pais de crianças entre os 18 e os 42M que respondessem a um questionário dividido em cinco áreas principais: dados relativos à criança, dados relativos à mãe, características da habitação, apoios (ama ou creche) e questões específicas relacionadas com o treino do bacio. Este era composto por perguntas de tipo misto (predominantemente fechadas), sendo adaptado caso a criança já tivesse iniciado ou não o TB (anexos I e II). Perante a ausência de um instrumento de medida (nacional ou internacional) validado que permitisse recolher os dados pretendidos, o questionário foi desenvolvido pelos autores, suportado por outros estudos publicados, nomeadamente relativos a etapas de desenvolvimento e outros fatores envolvidos na aquisição de controlo de esfíncteres. ${ }^{12-13}$ Após a sua construção, este foi aplicado, pelos três investigadores responsáveis pela colheita de informação na população, a uma amostra de 30 crianças seguidas em consulta de saúde infantil e juvenil dos centros de saúde onde decorreu o estudo, durante o mês de setembro de 2012. Foram reformuladas questões 
que levantaram mais dúvidas aquando do preenchimento do questionário, permitindo aprimorar a clareza e a simplicidade desejadas. No intuito de otimizar a compreensão e diminuir a subjetividade, cada um dos três investigadores envolvidos aplicou diretamente as questões no decurso da consulta, esclarecendo dúvidas e clarificando conceitos, num período de tempo estimado em 10 minutos.

As crianças com atraso de desenvolvimento psicomotor ou patologias crónicas que interfiram na aquisição de controlo de esfíncteres, crianças gémeas ou crianças cujos dados eram insuficientes para a realização do estudo foram excluídas. Consideramos o treino do bacio como completo quando a criança consegue controlo de esfíncteres diurno e noturno, conseguindo manter-se seca, exceto um a dois acidentes, durante pelo menos um mês. ${ }^{12}$

Os resultados foram avaliados tendo em conta a idade de início e de término do treino do bacio, calculando a sua duração e considerando dados sociodemográficos como o sexo, a idade materna, o nível educacional e ocupação, a classe social, o número de filhos, o principal motivo para dar início ao treino do bacio, o local escolhido e o método utilizado. Às crianças que já tinham completado o treino foi diferenciado o controlo de esfíncter anal e vesical.

O estudo foi aprovado pela Comissão de Ética para a Saúde da Administração Regional de Saúde do Norte e foi salvaguardada a confidencialidade.

Para a revisão bibliográfica pesquisaram-se guidelines, artigos de revisão e originais a partir das combinações de palavras-chave toilet training, potty training, development and toilet training, utilizando a base de dados da MEDLINE/PubMed, Google e sites de sociedades nacionais e internacionais de pediatria.

\section{Análise estatística}

Foi efetuada a análise descritiva dos dados sociodemográficos, apresentando os resultados sob a forma de médias com desvios-padrão (DP) ou medianas aquando de distribuição não paramétrica. As idades de início e término e a duração do TB foram comparadas, usando os testes T-student e ANOVA para as variáveis sexo, meio habitacional, escolaridade materna e empregabilidade materna. A significância estatística foi considerada quando $p<0,05$. Os dados foram analisados através do programa informático Statistical Package for Social Science (SPSS), versão 19.0.

\section{RESULTADOS}

\section{Dados sociodemográficos}

Foram incluídas 83 crianças, das quais 24 não tinham dado início ao TB (Quadro I). Analisamos os dados referentes às 59 restantes (Quadro II) e, destas, 31 eram do sexo masculino e a média de idades calculada foi de $31 \mathrm{M}(D P=9)$ (mediana 35M). No momento do preenchimento do questionário, 35 crianças frequentavam o infantário, 74\% das quais há mais de três meses.

Quanto às características maternas, 42 eram portuguesas e as restantes de outras nacionalidades (Quadro II).

A maioria das mães tinha entre 25 e 35 anos de idade $(\mathrm{n}=41)$, eram casadas $(\mathrm{n}=40)$, em média com 1,6 $(D P=0,8)$ filhos. Pertenciam à classe social média (Graffar III) $(n=36)$, tinham emprego $(n=37)$ e possuíam um nível de escolaridade entre 6 e 12 anos $(n=39)$.

\section{Iniciação e término do treino do bacio}

A idade de início do TB variou entre 9M e 40M (Figura 1) e em média ocorreu aos $22 \mathrm{M}(D P=7)$, sendo que 27 começaram antes dos $22 \mathrm{M} \mathrm{e} 32$ com 22 ou mais meses. Em raparigas e rapazes, a média de iniciação do TB foi $22 \mathrm{M}(D P=6)$ e $24 \mathrm{M}(D P=7)$, respetivamente $(p=$ $0,36)$.

As crianças do meio rural, filhos de mães empregadas e com escolaridade $\leq 5$ anos iniciaram o TB mais cedo. A idade mais precoce de início do TB encontrada foi 9M numa criança cuja mãe era natural da Índia.

Das crianças estudadas, 20 completaram o TB, sendo que 13 adquiriram primeiro o controlo de esfíncter vesical e nas sete restantes o controlo anal e vesical foi simultâneo. A duração do TB registou uma média de $3 \mathrm{M}$, mediana 2 [0-16] M. A idade média em que completaram o TB foi $27 \mathrm{M}(D P=7)$, sendo $26 \mathrm{M}(D P=7)$ nas raparigas e $27 \mathrm{M}(D P=7)$ nos rapazes (Quadro III).

O grupo que iniciou mais cedo completou também mais cedo o TB $(p=0,005)$; contudo, a duração até aquisição de controlo de esfíncteres foi também maior ( $p=$ 0,046) (Figura 2).

\section{Métodos utilizados e motivos para iniciação}

A maioria dos pais questionados recebeu informação sobre o tema através de familiares e de cuidadores 


\begin{tabular}{|c|c|}
\hline \multicolumn{2}{|c|}{$\begin{array}{l}\text { QUADRO I. Caracterização sociodemográfica do grupo } \\
\text { que não iniciou o treino do bacio }\end{array}$} \\
\hline $\begin{array}{l}\text { Características } \\
\text { criança }(n=24)\end{array}$ & $\mathbf{n}$ \\
\hline Sexo & Masculino: 16 \\
\hline Média idades & $21 \mathrm{M}(D P=3)[18-28]$ \\
\hline Meio habitacional & $\begin{array}{l}\text { Urbano: } 16 \\
\text { Rural: } 8\end{array}$ \\
\hline Apoios & Infantário: 11 \\
\hline Características maternas & $\mathbf{n}$ \\
\hline Nacionalidade & $\begin{array}{l}\text { Portugal: } 18 \\
\text { Brasil: } 2 \\
\text { China: } 1 \\
\text { Mónaco: } 1 \\
\text { África do Sul: } 1 \\
\text { Guiné Bissau: } 1\end{array}$ \\
\hline Idade & $\begin{array}{l}<25 \text { anos: } 6 \\
25-35 \text { anos: } 15 \\
>35 \text { anos: } 3\end{array}$ \\
\hline Estado civil & $\begin{array}{l}\text { Casada: } 13 \\
\text { Solteira: } 3 \\
\text { União de facto: } 8\end{array}$ \\
\hline N. ${ }^{\circ}$ filhos & $\begin{array}{l}\text { 1:14 } \\
\geq 2: 10 \\
\text { Média: } 1,4(D P=0,6)\end{array}$ \\
\hline Classe social (Graffar) & $\begin{array}{l}\text { Classe I: } 0 \\
\text { Classe II: } 5 \\
\text { Classe III: } 14 \\
\text { Classe IV: } 5 \\
\text { Classe V: } 0\end{array}$ \\
\hline Ocupação & $\begin{array}{l}\text { Empregadas: } 13 \\
\text { Desempregadas: } 11\end{array}$ \\
\hline Escolaridade & $\begin{array}{l}<6 \text { anos: } 2 \\
6-12 \text { nos: } 10 \\
>12 \text { anos: } 12\end{array}$ \\
\hline
\end{tabular}

DP, desvio padrão; $M$, meses.

no infantário ( $\mathrm{n}=27)$; uma pequena percentagem referiu ter falado deste assunto com o médico $(n=7)$ ou enfermeiro $(n=5)$ no decorrer das consultas (Figura 3$)$. O bacio foi o lugar escolhido por 32 dos inquiridos e os

\begin{tabular}{|c|c|}
\hline \multicolumn{2}{|c|}{$\begin{array}{l}\text { QUADRO II. Caracterização sociodemográfica do grupo } \\
\text { que iniciou o treino do bacio }\end{array}$} \\
\hline $\begin{array}{l}\text { Características criança } \\
(n=59)\end{array}$ & $\mathrm{n}$ \\
\hline Sexo & Masculino: 31 \\
\hline Média idades & $31 \mathrm{M}(D P=9)[18-42]$ \\
\hline Meio habitacional & $\begin{array}{l}\text { Urbano: } 35 \\
\text { Rural: } 24\end{array}$ \\
\hline Apoios & Infantário: 35 \\
\hline Características maternas & $\mathrm{n}$ \\
\hline Nacionalidade & $\begin{array}{l}\text { Portugal: } 42 \\
\text { Brasil: } 5 \\
\text { Roménia: } 3 \\
\text { Ucrânia: } 3 \\
\text { França: } 3 \\
\text { Índia: } 1 \\
\text { Canadá: } 1 \\
\text { Cabo Verde: } 1\end{array}$ \\
\hline Idade & $\begin{array}{l}<25 \text { anos: } 10 \\
25-35 \text { anos: } 41 \\
>35 \text { anos: } 8\end{array}$ \\
\hline Estado civil & $\begin{array}{l}\text { Casada: } 40 \\
\text { Solteira: } 8 \\
\text { União de facto: } 11\end{array}$ \\
\hline N. ${ }^{\circ}$ filhos & $\begin{array}{l}1: 32 \\
\geq 2: 27 \\
\text { Média: } 1,6(\mathrm{DP}=0,8)\end{array}$ \\
\hline Classe social (Graffar) & $\begin{array}{l}\text { Classe I: } 0 \\
\text { Classe II: } 11 \\
\text { Classe III: } 36 \\
\text { Classe IV: } 11 \\
\text { Classe V: } 1\end{array}$ \\
\hline Ocupação & $\begin{array}{l}\text { Empregadas: } 37 \\
\text { Desempregadas: } 22\end{array}$ \\
\hline Escolaridade & $\begin{array}{l}<6 \text { anos: } 4 \\
\text { 6-12 anos: } 39 \\
>12 \text { anos: } 16\end{array}$ \\
\hline
\end{tabular}

$D P$, desvio padrão; $M$, meses.

métodos mais utilizados foram o reforço positivo (oferecer brinquedos, carinhos, palmas, algo do seu agra- 


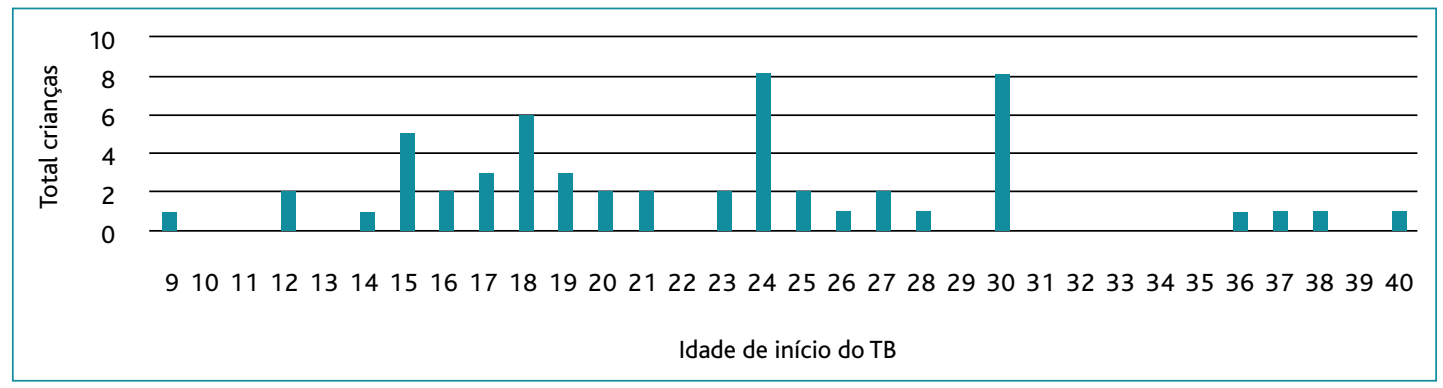

Figura 1. Idade de início do TB (meses).

\section{QUADRO III. Fatores sociodemográficos associados com o TB}

\begin{tabular}{|c|c|c|c|c|}
\hline \multicolumn{2}{|c|}{$\begin{array}{l}\text { Fator associado com o TB } \\
(n=59)\end{array}$} & $\begin{array}{l}\text { Idade início (M) } \\
\text { média (DP) }\end{array}$ & $\begin{array}{l}\text { Idade fim (M) } \\
\text { média }(D P)\end{array}$ & $\begin{array}{c}\text { Duração do TB }(M) \\
\text { média }(D P)\end{array}$ \\
\hline Sexo & $\begin{array}{l}\text { Masculino (31) } \\
\text { Feminino (28) }\end{array}$ & $\begin{array}{r}24(D P=7) \\
22(D P=6) \\
P=0,360\end{array}$ & $\begin{array}{r}27(D P=7) \\
26(D P=7) \\
P=0,785\end{array}$ & $\begin{array}{l}2(D P=2) \\
4(D P=4) \\
P=0,206\end{array}$ \\
\hline Meio habitacional & $\begin{array}{l}\text { Urbano (35) } \\
\text { Rural (24) }\end{array}$ & $\begin{array}{r}24(D P=7) \\
21(D P=6) \\
P=0,097\end{array}$ & $\begin{array}{r}28(D P=7) \\
25(D P=7) \\
P=0,429\end{array}$ & $\begin{array}{l}2(D P=3) \\
4(D P=6) \\
P=0,698\end{array}$ \\
\hline $\begin{array}{l}\text { Escolaridade } \\
\text { materna }\end{array}$ & $\begin{array}{l}<6 \text { anos (4) } \\
6-12 \text { anos (39) } \\
>12 \text { anos (16) }\end{array}$ & $\begin{array}{r}20(D P=4) \\
24(D P=7) \\
21(D P=5) \\
P=0,187\end{array}$ & $\begin{array}{r}20(D P=5) \\
29(D P=7) \\
26(D P=7) \\
P=0,150\end{array}$ & $\begin{array}{l}1(D P=1) \\
2(D P=1) \\
6(D P=7) \\
P=0,077\end{array}$ \\
\hline Mãe empregada & $\begin{array}{l}\operatorname{Sim}(37) \\
\text { Não (22) }\end{array}$ & $\begin{array}{r}22(D P=6) \\
24(D P=8) \\
P=0,210\end{array}$ & $\begin{array}{r}25(D P=8) \\
29(D P=6) \\
P=0,277\end{array}$ & $\begin{array}{l}3(D P=5) \\
2(D P=1) \\
P=0,282\end{array}$ \\
\hline
\end{tabular}

$D P$, desvio padrão; $M$, meses; $T B$, treino do bacio.

do) $(n=37)$ e mostrar exemplos (de irmãos, adultos ou bonecos) $(\mathrm{n}=18)$. O principal motivo referido para iniciar foi a idade $(\mathrm{n}=17)$ e sentir a criança preparada (n = 13) por manifestar sinais de maturidade comunicativa e motora; outros motivos: ser mais prático $(n=10)$, ia iniciar a creche $(n=8)$, despesas com as fraldas $(n=$ 6), experiência com filhos anteriores $(n=3)$ e a estação do ano $(n=2)$. Os meses de verão foram os escolhidos por 49 dos inquiridos como altura preferencial para o treino.

\section{DISCUSSÃO}

Neste estudo foi investigada uma população de crianças do norte do país inseridas em diferentes meios socioculturais.

Verificamos nesta amostra que as crianças do meio rural, filhas de mães empregadas e com escolaridade $\leq 5$ anos iniciaram o TB mais cedo e a iniciação precoce do treino se correlacionou com uma idade mais precoce de aquisição de controlo de esfíncteres, mas também com maior duração do TB.

Relativamente ao conhecimento sobre o assunto, familiares e cuidadores no infantário representaram a principal fonte de informação; apenas uma pequena parte referiu ter falado sobre o tema com o médico assistente.

As expectativas parentais, no que respeita àquele que consideram ser o momento certo para iniciar o TB, fizeram com que a idade da criança fosse enumerada por $1 / 3$ dos inquiridos como um motivo suficiente para determinar o início do treino, nem sempre reconhecendo a importância dos sinais de maturidade. De sublinhar, no entanto, que uma proporção de cuidadores optou por aguardar pelos sinais de que a criança se mostrava preparada, através da observação atenta do seu comportamento, uma capacidade sublinhada como fundamental por Brazelton. ${ }^{8}$ Esta noção de "pre- 

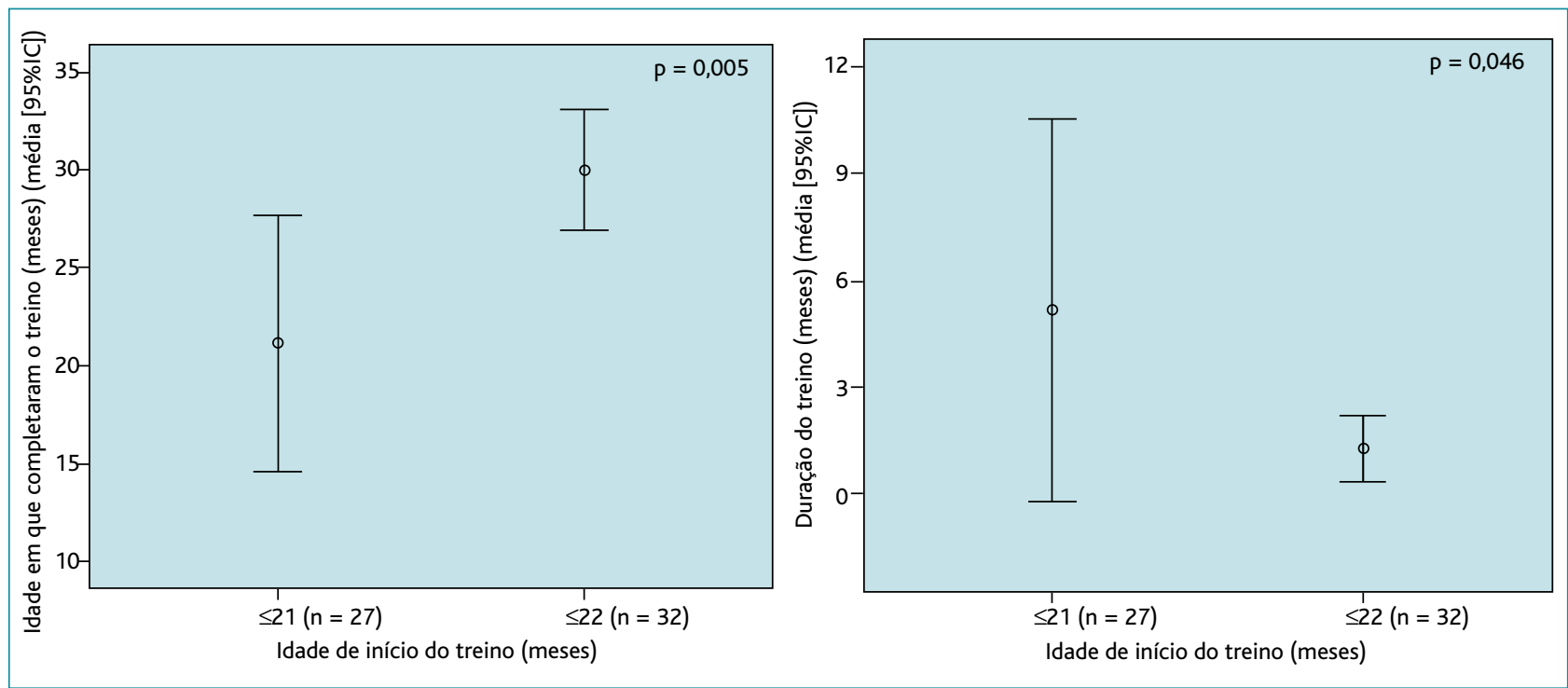

Figura 2. Média e intervalo de confiança de 95\% para a idade de término (esquerda) e duração (direita) do TB baseado na idade de início do treino.

paração" pressupõe a valorização de determinadas competências: a capacidade de seguir direções, perceber as suas necessidades, conseguir momentos secos, ter o desejo de permanecer seco e ter a capacidade de se sentar e vestir e despir. ${ }^{1}$

Também a altura do ano teve influência; a maioria dos inquiridos referiu que prefere esperar pelos meses quentes, quando há menos roupa e a tarefa parece facilitada.

O sucesso na aquisição de controlo dos esfíncteres foi conseguido após um período de 3M (em média), utilizando estratégias que passaram sobretudo pelo reforço positivo e no mostrar exemplos, o que vai ao encontro de uma abordagem mais liberalista determinada pela criança; apenas uma pequena parte dos cuidadores $(n=2)$ utilizou estratégias de punição para o treino.

A idade de início do treino é diferente entre países e, dentro destes, varia também entre diferentes grupos. ${ }^{12}$ Nos países ocidentais, a maioria das crianças inicia o TB entre os 21 e os 36M, tendo-se encontrado uma tendência para a iniciação em idades cada vez mais tardias. ${ }^{14} \mathrm{Um}$ estudo realizado na Bélgica ${ }^{15}$ comparou as idades de iniciação do TB em três gerações consecutivas e mostrou que, aos $18 \mathrm{M}$, a percentagem encontrada foi de $88 \%, 50 \%, 22 \%$, verificando-se assim que as ge- rações mais novas iniciam o TB mais tarde. Nos Estados Unidos da América (EUA), ${ }^{1}$ a idade média de iniciação do TB tem vindo a aumentar nas últimas décadas, passando dos 18M nos anos 1940 aos 27M em 1980 e 37M em 2003. Aos 48M, praticamente todas as crianças já adquiriram controlo de esfíncteres. ${ }^{16}$

A idade de iniciação do TB encontrada nesta amostra foi similar à dos países ocidentais, ${ }^{14}$ verificando-se no nosso estudo uma tendência para iniciar em idade mais precoce nos filhos de mães empregadas, com menos instrução académica e a viver em meio rural. Estes factos podem eventualmente estar relacionados com a pressão atual dos infantários no aconselhamento de que o TB tenha já ocorrido antes da respetiva admissão (aos três anos) (14\% dos inquiridos afirmaram ter sido essa a razão para iniciar o TB), questões económicas $(10 \%)$ e uma abordagem mais tradicional. ${ }^{13,16}$

A forma como a idade de início influencia o treino não está ainda bem esclarecida. ${ }^{7}$ Parece, no entanto, haver pouco benefício em iniciar o TB em idades muito jovens, já que a iniciação precoce do treino se correlacionou com uma idade mais precoce de aquisição de controlo de esfíncteres, mas também com maior duração do TB, resultados encontrados na nossa amostra e também em estudos noutros países. ${ }^{12,17}$ Fica, assim, realçado que o TB é inerente a um processo do desen- 


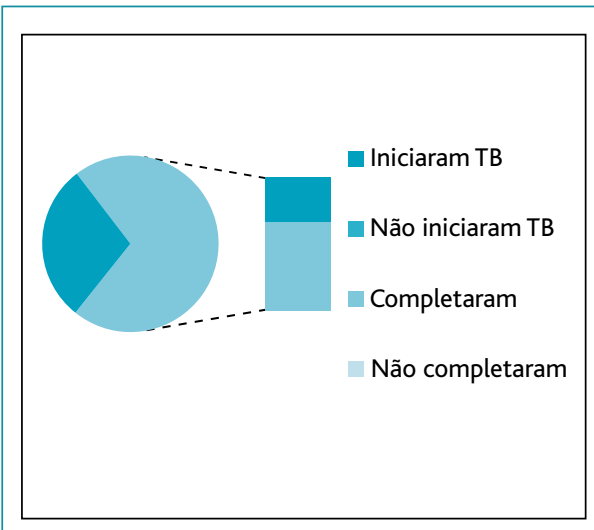

Gráfico 1. Distribuição da amostra analisada.

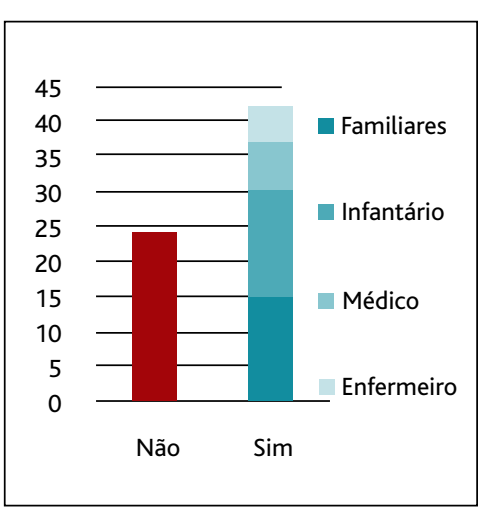

Gráfico 2. Recebeu informação sobre o tema?

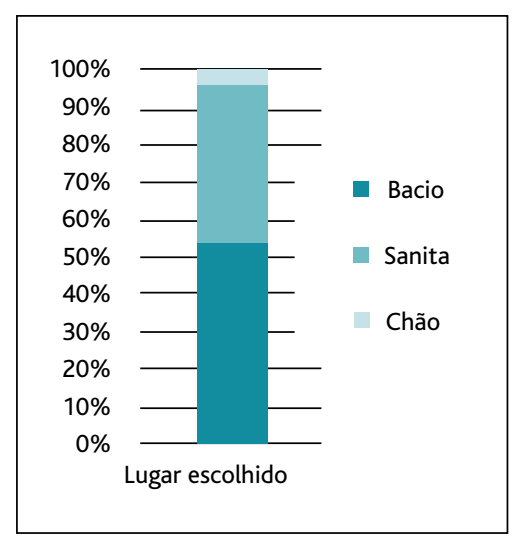

Gráfico 4. Que lugar escolheu para iniciar o TB?

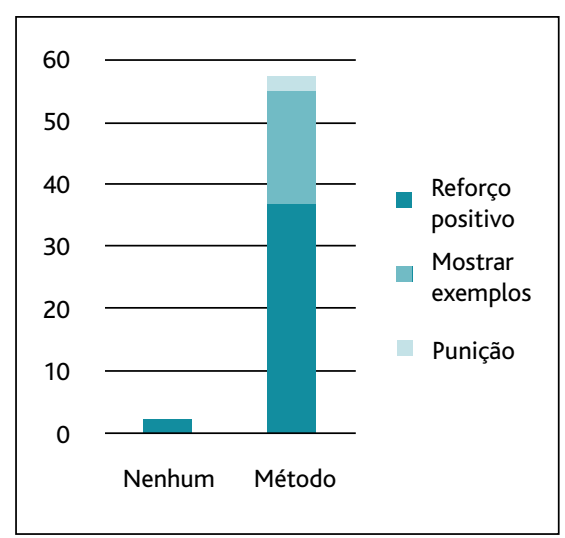

Gráfico 5. Que método usou para que resultasse?

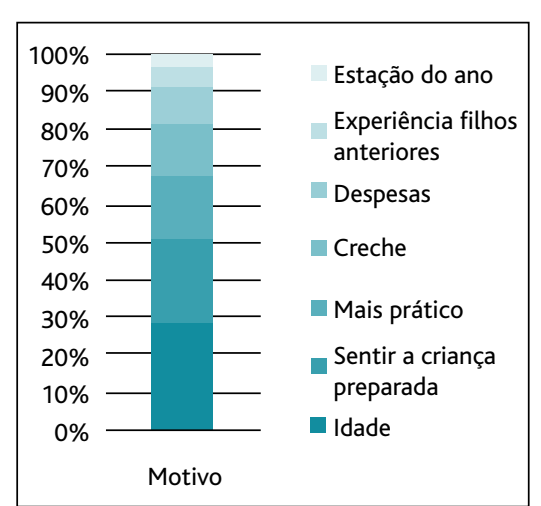

Gráfico 3. Qual foi o principal motivo para iniciar o TB?

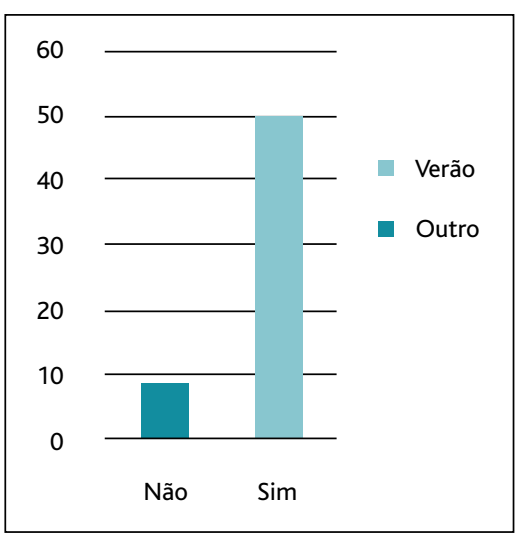

Gráfico 6. Acha que a altura do ano é importante? Se sim, qual?

Figura 3. Características sociodemográficas e respostas obtidas relativamente a alguns fatores associados com o TB na amostra analisada.

volvimento, dependente da maturidade neurofisiológica e comportamental. ${ }^{14}$

Nesta amostra, a criança que iniciou o TB em idade mais precoce (início aos 9M) é filha de pais naturais da Índia, o que apoia a variação intercultural quanto às expectativas.

De acordo com a literatura, existem diferentes perspetivas para o TB quanto a rapazes ou raparigas, acreditando-se que os rapazes começam e terminam o treino mais tarde do que as raparigas, ${ }^{9-10}$ o que acabou por verificar-se também na amostra analisada no presente estudo. De facto, trabalhos apresentados pelos EUA ${ }^{1}$ apontam neste sentido: em média, as raparigas adquirem controlo de esfíncter vesical aos $32,5 \mathrm{M}$ e os rapa- zes aos 35M; os valores correspondentes para o treino de esfíncter anal são, respetivamente, 31,5M e 34,7M. Para ambos os sexos, a capacidade de controlo de esfíncter anal noturno é uma habilidade precoce, ao contrário do controlo vesical noturno que habitualmente é o mais tardio. ${ }^{16}$

O nosso trabalho apresenta limitações: o desenho de estudo (transversal e amostragem) e a construção do questionário (não validado). Atendendo às limitações metodológicas e possíveis vieses, este estudo apenas poderá ser considerado exploratório.

\section{CONCLUSÃO}

A transição para TB apresenta grande variabilidade 
de fatores; nesta amostra, verificamos que crianças do sexo feminino, filhos de mães empregadas e com menos instrução académica, a viver em meio rural, iniciaram o TB mais cedo. Existiu uma diferença estatisticamente significativa entre iniciar o TB em idade mais jovem e a aquisição de controlo de esfíncteres mais precoce, mas também com maior duração do TB.

Os familiares ou cuidadores no infantário constituíram a principal fonte de orientação neste assunto. Reforço positivo e mostrar exemplos foram as principais estratégias utilizadas pelos pais questionados neste trabalho para conseguir obter sucesso no TB.

Reconhece-se que é difícil a tarefa de aconselhar, dada a escassez de estudos (os existentes são sobretudo descritivos) e a ausência atual de evidência da superioridade de um método em relação ao outro ${ }^{14}$ - mais estudos seriam necessários, em larga escala, para estabelecer recomendações médicas baseadas na evidência.

\section{REFERÊNCIAS BIBLIOGRÁFICAS}

1. Howell DM, Wysocki K, Steiner MJ. Toilet training. Pediatr Rev. 2010;31(6):262-3.

2. Klassen TP, Kiddoo D, Lang ME, Friesen C, Russell K, Spooner $C$, et al. The effectiveness of different methods of toilet training for bowel and bladder control. Evid Rep Technol Assess (Full Rep). 2006;(147):1-57.

3. Mota DM, Barros AJ. Toilet training: methods, parental expectations and associated dysfunctions. J Pediatr (Rio J). 2008;84(1):9-17.

4. American Academy of Pediatrics. American Academy of Pediatrics [homepage]. Elk Grove Village (IL):AAP; 2015 [cited 2015 Mar 7]. Available from: http://www.aap.org/

5. Canadian Paediatric Society. Caring for kids = Soin de nos enfants [homepage]. Ottawa (ON): CPS; 2013 [cited 2015 Mar 7]. Available from: http://www.caringforkids.cps.ca/handouts/toilet_learning

6. FamilyDoctor.org. Toilet training your cild [homepage]. Leawood (KS): American Academy of Family Physicians; 1996 [revised 2010 Nov; cited 2015 Mar 7]. Available from: http://familydoctor.org/familydoctor/en/kids/toileting/toilet-training-your-child.html

7. Choby BA, George S. Toilet training. Am Fam Physician. 2008;78(9):1059-1064.
8. Brazelton TB. A child-oriented approach to toilet training. Pediatrics. 1962;29:121-8.

9. Foxx RM, Azrin NH. Dry pants: a rapid method of toilet training children. Behav Res Ther. 1973;11(4):435-42.

10. Schum TR, Kolb TM, McAuliffe TL, Simms MD, Underhill RL, Lewis M. Sequential acquisition of toilet-training skills: a descriptive study of gender and age differences in normal children. Pediatrics. 2002;109(3):E48.

11. de Vries MW, de Vries MR. Cultural relativity of toilet training readiness: a perspective from East Africa. Pediatrics. 1977;60(2):170-7.

12. Koc I, Camurdan AD, Beyazova U, Ithan MN, Sahin F. Toilet training in Turkey: the factors that affect timing and duration in different sociocultural groups. Child Care Health Dev. 2008;34(4):475-81.

13. Mota DM, Barros AJ. Toilet training: situation at 2 years of age in a birth cohort. J Pediatr (Rio J). 2008;84(5):455-62.

14. Kaerts N, Van Hal G, Vermandel A, Wyndaele JJ. Readiness signs used to define the proper moment to start toilet training: a review of the literature. Neurourol Urodyn. 2012;31(4):437-40.

15. Bakker E, Wyndaele JJ. Changes in the toilet training of children during the last 60 years: the cause of an increase in lower urinary tract dysfunction? BJU Int. 2000;86(3):248-52.

16. Vermandel A, Van Kampen M, Van Gorp C, Wyndaele JJ. How to toilet train healthy children? A review of the literature. Neurourol Urodyn. 2008;27(3):162-6.

17. Blum NJ, Taubman B, Nemeth N. Relationship between age at initiation of toilet training and duration of training: a prospective study. Pediatrics. 2003;111(4 Pt 1):810-4.

\section{CONFLITO DE INTERESSES}

Os autores declaram não ter conflitos de interesses.

\section{COMISSÃO DE ÉTICA}

Estudo realizado com parecer favorável da Comissão de Ética para a Saúde da ARS Norte.

\section{ENDEREÇO PARA CORRESPONDÊNCIA}

Ângela Pereira

Serviço de Pediatria, Hospital de Braga

Sete Fontes, 4710-243 São Victor, Braga

E-mail: chelacbr@hotmail.com

Recebido em 14-09-2014

Aceite para publicação em 16-04-2015

Artigo escrito ao abrigo do novo acordo ortográfico. 


\begin{abstract}
TOILET TRAINING: AN OBSERVATIONAL STUDY IN A SAMPLE OF HEALTHY CHILDREN BETWEEN 18 AND 42 MONTHS OLD

Introduction: Toilet training is an important stage in child development. There are few studies and guidelines and our bibliographic research found no national epidemiological data on this subject. The aim of the present study was to determine the patterns of toilet training in a Portuguese population, the factors that may be related to its timing and duration, and methods used.

Methods: In this cross-sectional study we selected a convenience sample of children who were seen in three primary healthcare centers. Data were collected using a questionnaire given to parents of children between 18 and 42 months old (M). Children with chronic conditions that affect bladder and bowel control, twins, and replies with incomplete data were excluded. Results: Eighty three questionnaires were completed. In 24, the child had not started toilet training. Of the remaining 59 repies, 31 were from boys, with a mean age of $31 \mathrm{M}$ [standard deviation (SD)=9]. Mean initiation and completion ages of training were $22 \mathrm{M}(S D=7)$ and $27 \mathrm{M}(\mathrm{SD}=7)$ respectively (earlier in girls). Families living in rural settlements, employed mothers and mothers with less than 5 years of formal education started training earlier. Of the 20 children who completed toilet training, the mean duration was $3 \mathrm{M}$ (median $2 \mathrm{M}[0-16 \mathrm{M}]$ ). Early initiation of intensive toilet training correlates with an earlier age at completion of training $(p=0.005)$ but also a longer duration $(p=0.046)$. The most methods most frequently employed by caregivers were positive reinforcement training and showing examples.

Conclusions: Toilet training shows a high variability of factors in this population. We found that female children of employed mothers with less formal education living in rural areas initiate toilet training earlier. There was a statistically significant difference between starting toilet training at a younger age and the acquisition of control of sphincters earlier, but with longer duration of training.
\end{abstract}

Keywords: Children; Child Development; Toilet Training.

\title{
ANEXO I \\ Questionário aplicado às crianças que ainda não iniciaram o treino do bacio.
}

1. DADOS RELATIVOS À CRIANÇA

Sexo: $M \square \quad F \square$;

Data de nascimento:

Peso ao nascer: l

Tempo de gestação (semanas):

Tipo de parto (vaginal, cesariana, ...):

2. DAdOS RELATIVOS À MÃE

Idade (anos à altura do nascimento da criança):

Naturalidade: Portugal $\square$; Outro país $\square$ qual?

Estado civil:

Nível escolaridade ( $n^{\circ}$ anos de escolaridade):

Número total de filhos: Idades:

Emprego: fora de casa $\square$; casa
3. CARATERÍSTICAS DA HABITAÇÃO

Número de crianças em casa:

Nível económico (escala de Graffar):

4. APOIOS

Frequenta infantário $S \square \mathrm{N}$ (Idade início infantário: ___

Frequenta ama $\mathrm{S} \square \mathrm{N} \square$;

Fica ao cuidado da mãe $\mathrm{S} \square \mathrm{N} \square$;

Outro (qual?)

5. QUESTIONÁRIO

5.1 Em que idade pensa iniciar o treino do bacio (em meses)? 
5.2 Recebeu informação acerca do tema? S

- Sim, no médico

- Sim, através de familiares

- Sim, através do infantário/ama

- Sim, outros

Quais?

5.3 Qual será a principal razão para iniciar o treino do bacio?

- idade $\square$

- vontade da criança

- despesas com as fraldas

- é mais prático

- quando iniciar a creche

- experiência com filhos anteriores

- outros sinais da criança $\square$ Quais?

5.4 Que método utilizará para que o treino resulte? - punição/castigos se tiver acidentes $\mathrm{S} \square \mathrm{N} \square$

- acordar a criança durante a noite para ir à casa-debanho $\mathrm{S} \square \mathrm{N} \square$

- reforço positivo (oferecer brinquedos, carinhos, palmas, algo do seu agrado) $\mathrm{S} \square \mathrm{N} \square$

- mostrar exemplos de irmãos/adultos/bonecos que usam a casa-de-banho $\mathrm{S} \square \mathrm{N}$

- outro $\square$ Qual?

- nenhum

5.5 Quais as consequências que acha que esta fase tem para a família?
- discussões familiares $\mathrm{S} \square \mathrm{N} \square$

- mãe/pai dormiu menos S $\square \mathrm{N} \square$

- criança dorme menos/ mais irritada $\mathrm{S} \square \mathrm{N} \square$

- outras $\square$ Quais?

- nenhuma

5.6 Acha que existe diferença entre os sexos?

$\mathrm{S} \square \mathrm{N} \square$

- Se respondeu sim, quem acha que consegue mais cedo? Rapaz $\square$; Rapariga

5.7 Acha que a altura do ano interfere no sucesso do treino do bacio? $\mathrm{S} \square \mathrm{N}$

- Se respondeu sim, qual considera a melhor altura do ano?

5.8 Em que lugar pensa iniciar o treino do bacio?

- bacio $\mathrm{S} \square \mathrm{N} \square$

- sanita $\mathrm{S} \square \mathrm{N} \square$

- outros $\mathrm{S} \square \mathrm{N} \square$ Quais?

5.9 Que tipo de fralda usa?

- descartáveis S $\square \mathrm{N}$

- pano $\square \mathrm{N}$

5.10 Onde dorme a criança?

- com os pais

- quarto próprio

- outro $\square$ Qual?

\section{ANEXO II}

Questionário aplicado às crianças que já iniciaram o treino do bacio.

1. DADOS RELATIVOS À CRIANÇA

Sexo: $M \square \quad F \square$;

Data de nascimento: ${ }^{\prime}-{ }_{\mathrm{Kg}}^{\prime}$

Peso ao nascer:

Tempo de gestação (semanas):

Tipo de parto (vaginal, cesariana, ...):

2. DADOS RELATIVOS À MÃE

Idade (anos à altura do nascimento da criança):

Naturalidade: Portugal $\square$; Outro país $\square$ qual?

Estado civil:

Nível escolaridade ( $\mathrm{n}^{\circ}$ anos de escolaridade):

Número total de filhos: Idades:

Emprego: fora de casa $\square$; casa
3. CARATERÍSTICAS DA HABITAÇÃO

Número de crianças em casa:

Nível económico (escala de Graffar):

\section{APOIOS}

Frequenta infantário $\mathrm{S} \square \mathrm{N}$ (Idade início infantário: Frequenta ama $\mathrm{S} \square \mathrm{N} \square$; Fica ao cuidado da mãe $S \square \quad \mathrm{N} \square$; Outro (qual?)

\section{QUESTIONÁRIO}

5.1 Em que idade decidiu iniciar o treino do bacio (em meses)? 
Considerar a $1 .^{\mathrm{a}}$ vez em que lhe falou sobre o tema ou the mostrou o bacio

5.2 Recebeu informação acerca do tema? S $\square \mathrm{N}$ - Sim, no médico

- Sim, através de familiares

- Sim, através do infantário/ama

- Sim, outros $\square$ Quais?

5.3 Qual será a principal razão para iniciar o treino do bacio?

- idade $\square$

- vontade da criança $\square$

- despesas com as fraldas

- é mais prático

- iniciar a creche

- experiência com filhos anteriores

- outros sinais da criança $\square$ Quais?

5.4 Que método utilizará para que o treino resulte? - punição/castigos se tiver acidentes $\mathrm{S} \square \mathrm{N} \square$

- acordar a criança durante a noite para ir à casa-debanho $\mathrm{S}$

- reforço positivo (oferecer brinquedos, carinhos, palmas, algo do seu agrado) $\mathrm{S} \square \mathrm{N}$

- mostrar exemplos de irmãos/adultos/bonecos que usam a casa-de-banho $\mathrm{S} \square \mathrm{N} \square$

- outro $\square$ Qual?

- nenhum

5.5 Já completou o treino? S $\square \mathrm{N}$ (considere a altura em que conseguiu manter-se seco por mais de 1 mês, excepto 1 a 2 acidentes)

- Se respondeu sim, com que idade, em meses, conseguiu completar o treino do bacio?

5.6 Qual conseguiu primeiro?

- treino para o xixi
- treino para o cócó

5.7 Quais as consequências que acha que esta fase tem para a família?

- discussões familiares $S \square N \square$

- mãe/pai dormiu menos $\mathrm{S} \square \mathrm{N} \square$

- criança dorme menos/ mais irritada $S \square N$

- outras $\square$ Quais?

- nenhuma

5.8 Acha que existe diferença entre os sexos?

$\mathrm{S} \square \mathrm{N} \square$

- Se respondeu sim, quem acha que consegue mais cedo? Rapaz $\square$; Rapariga

5.9 Acha que a altura do ano interfere no sucesso do treino do bacio? $\mathrm{S} \square \mathrm{N}$

- Se respondeu sim, qual considera a melhor altura do ano?

5.10 Que lugar decidiu usar para o treino do bacio?

- bacio $\mathrm{S} \square \mathrm{N}$

- sanita $\mathrm{S} \square \mathrm{N} \square$

- outros $\mathrm{S} \square \mathrm{N} \square$ Quais?

5.11 Nas que usam sanita:

- Também usa redutor de sanita? S $\square \mathrm{N} \square$

- Também usa apoio para os pés? S $\square$ N

5.12 Que tipo de fralda usa?

- descartáveis S $\square \mathrm{N}$

- pano $\square \mathrm{N}$

- ambas?

5.13 Onde dorme a criança?

- com os pais

- quarto próprio $\square$

- outro $\square$ Qual? 